\title{
Atopic dermatitis in the view of pediatrics
}

\author{
Anca E Chiriac ${ }^{1}$, Anca Chiriac², Letitia Duceac ${ }^{3}$, Doina Azoicai ${ }^{4}$
}

${ }^{1}$ University of Medicine and Pharmacy Grigore T. Popa, Faculty of Medicine- PhD Student, Iasi, Romania, ${ }^{2}$ Apollonia University, Nicolina Medical Center, Dermatology Department, P. Poni Institute of Macromolecular Chemistry, Iasi, Romania, ${ }^{3}$ Apollonia University, Saint Mary Childrens Hospital, Epidemiology Department, Iasi, Romania, ${ }^{4}$ University of Medicine and Pharmacy Grigore T. Popa, Faculty of Medicine, Department of Epidemiology, Iasi, Romania

Corresponding author: Prof. Anca Chiriac, E-mail: ancachiriac@yahoo.com

Sir,

In 2014 we performed a study on 1000 kindergarten children and we concluded a point prevalence of atopic dermatitis extremely low: $0,22 \%$ [1].

In 2020, in the same geographic area, we performed a retrospective study, between 2013 and 2018, revising all medical records of the children (aged 0-16) hospitalized in the Saint Mary Children Hospital Iasi. We selected only skin diseases (main or second diagnosis). Each diagnosis was performed by pediatrics without any dermatological examination (Table 1).

Evaluating the medical records some observations were made:

- Skin diseases were categorized differently from dermatological point of view;
- Psoriasis, vitiligo, alopecia areata and other were summarized as other dermatitis;

- Seborrheic dermatitis was highly prevalent, but divided into infantile and non-infantile type;

- Scalp seborrhea was considered a specific diagnosis;

- diaper dermatitis was reported in almost the same proportion as atopic dermatitis;

- Total number of skin disorders did not vary too much for the entire period (2013-2018);

- Prevalence of atopic dermatitis was reported to vary from $2.74 \%$ to $4.06 \%$ of all skin diseases for hospitalized children.

Atopic dermatitis is a very important diagnosis for pediatrics, more than psoriasis for example, but one can doubt the validity of diagnostic criteria, as well as the identification of other skin diseases. Another

\begin{tabular}{|c|c|c|c|c|c|c|}
\hline Diagnosis & 2018 & 2017 & 2016 & 2015 & 2014 & 2013 \\
\hline Piodermitis & 45 & 37 & 24 & 51 & 47 & 43 \\
\hline Pemphigus & 1 & 1 & 0 & 1 & 0 & 0 \\
\hline Epidermolysis bullosa & 1 & 1 & 1 & 0 & 0 & 1 \\
\hline Dermatitis herpetiformis & 1 & 3 & 0 & 1 & 1 & 0 \\
\hline Prurigo & 2 & 4 & 5 & 8 & 9 & 20 \\
\hline Atopic dermatitis & $192(2,74 \%)$ & $208(3,58 \%)$ & $234(3,88 \%)$ & $250(3,58 \%)$ & $229(4,06 \%)$ & $217(3,70 \%)$ \\
\hline Scalp seborrhea & 9 & 3 & 5 & 8 & 5 & 8 \\
\hline Infantile seborrheic dermatitis & 18 & 4 & 4 & 11 & 14 & 13 \\
\hline Seborrheic dermatitis & 43 & 52 & 40 & 60 & 42 & 47 \\
\hline Diaper dermatitis & 167 & 200 & 213 & 225 & 138 & 125 \\
\hline Allergic contact dermatitis & 51 & 47 & 51 & 66 & 78 & 119 \\
\hline Irritant contact dermatitis & 22 & 26 & 39 & 23 & 6 & 7 \\
\hline Contact dermatitis & 2 & 8 & 6 & 13 & 14 & 15 \\
\hline Food allergy & 1 & 5 & 6 & 16 & 6 & 8 \\
\hline Oral contact allergy & 1 & 0 & 1 & 0 & 0 & 0 \\
\hline Burns & 1 & - & - & - & - & - \\
\hline Other dermatitis & 25 & 34 & 23 & 38 & 25 & 23 \\
\hline Total & 527 & 580 & 602 & 698 & 564 & 585 \\
\hline
\end{tabular}

How to cite this article: Chiriac AE, Chiriac A, Duceac L, Azoicai D. Atopic dermatitis in the view of pediatrics. Our Dermatol Online. 2020;11(e):e180.1-e180.2. Submission: 01.04.2020; Acceptance: 08.06.2020

DOI: $10.7241 /$ ourd.2020e.180 
explanation could rely on the attention focused on the atopic dermatitis, ignoring other skin diseases.

\section{Consent}

The examination of the patient was conducted according to the Declaration of Helsinki principles.

The authors certify that they have obtained all appropriate patient consent forms. In the form the patient(s) has/have given his/her/their consent for his/her/their images and other clinical information to be reported in the journal. The patients understand that their names and initials will not be published and due efforts will be made to conceal their identity, but anonymity cannot be guaranteed.

\section{REFERENCE}

1. Chiriac A, Foia L, Gorduza VE, Chiriac AE, Uliliuc T, Kezic S, et al. The puzzled low prevalence of atopic dermatitis in kindergarten children in Romania. Pediatr Allergy Immunol. 2014;25:96-7.

Copyright by Anca E Chiriac, et al. This is an open access article distributed under the terms of the Creative Commons Attribution License, which permits unrestricted use, distribution, and reproduction in any medium, provided the original author and source are credited.

Source of Support: Nil, Conflict of Interest: None declared. 